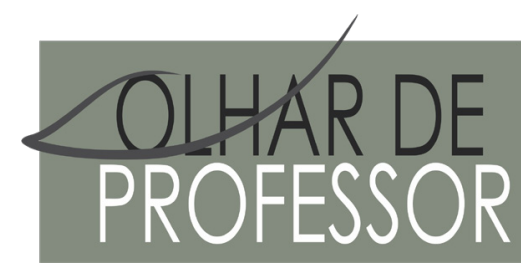

DOI: 10.5212/OLHARPROFR.v.23.2020.16025.209209226587.0615

\title{
RELATO DE EXPERIÊNCIA: A CONSTRUÇÃO DE SABERES/FAZERES PELO EMARANHADO DE VOZES NO/PELO COTIDIANO EM TEMPOS DE COVID-19
}

\author{
EXPERIENCE REPORT: THE CONSTRUCTION OF KNOWLEDGE-DOING NETWORKS THROUGH INTERWOVEN \\ VOICES ON AND THROUGH THE QUOTIDIAN IN COVID-19 TIMES \\ INFORME DE UNA EXPERIENCIA: LA CONSTRUCCIÓN DE SABERES/ QUEHACERES POR EL ENTRAMADO DE \\ VOCES EN LA COTIDIANIDAD EN TIEMPOS DE COVID-19
}

ELIZANDRA ROBERTA NEVES DE CARVALHO*

Resumo: O presente documento visa apresentar um relato de experiência enquanto professora de Inglês da educação básica de uma escola pública, descrevendo a construção de um trabalho interdisciplinar que vem sendo realizado neste momento de suspensão de aulas devido à pandemia da Covid-19. Dialogo com Freire e Certeau, especialmente, acerca da função social da escola e do currículo construído no e pelo cotidiano, a fim de tecer novas considerações a respeito do processo de ensino-aprendizagem, visando sua adequação, dado o momento sóciohistórico em que nos encontramos.

Palavras-chave: Cotidiano. Trabalho interdisciplinar. Saberes/fazeres docente.

\begin{abstract}
This paper aims to introduce the report of my experience as an Elementary English Teacher in a public school, describing the construction of an interdisciplinary work, which has been taking because of class suspension due to Covid-19 pandemic. A dialogue with Freire and Certeau, specially, is proposed to tackle both the social role of school and the curriculum built on and through the quotidian, in an attempt to make new considerations about the teaching/learning process, aiming its adjustment, considering the social-historical moment we are going through.
\end{abstract}

Keywords: Quotidian. Interdisciplinary work. Teachers’ knowledge and practice.

Resumen: Este documento tiene como objetivo presentar un informe de experiencia como profesor de inglés en la educación básica de una escuela pública, describiendo la construcción de un trabajo interdisciplinario que se está llevando a cabo en este momento por la suspensión de clases a causa de la pandemia de Covid-19. Un diálogo con Freire y Certeau, especialmente sobre la función social de la escuela y el plan de estudios integrado en la cotidianidad, para hacer nuevas consideraciones sobre el proceso de enseñanza-aprendizaje, en un intento de adaptarlo a este momento socio histórico en el que nos encontramos.

Palabras-clave: Cotidianidad. Trabajo interdisciplinario. Saberes/quehaceres docente.

\footnotetext{
* Mestre em Educação pela Universidade Estadual de Campinas. Professora de Língua Inglesa na Prefeitura Municipal de Campinas. Email: carvalhoelizandra@yahoo.com.br
} 


\section{INTRODUÇ̃̃̃O}

A pandemia da Covid-19 nos impôs o isolamento social como medida necessária à preservação da vida, afetando diversos setores da sociedade, inclusive o espaço escolar. De uma hora para outra, as carteiras ficaram vazias, as salas de aula emudeceram-se, cessou-se o movimento nos corredores, e a escola, destituída de vida, deixou de ser escola. Confinados agora em casa, enquanto professores, testemunhamos medidas provisórias e regulamentações serem divulgadas para legislar as ações educativas. Enquanto assistimos a colégios particulares se anteciparem e se adequarem, fazendo uso de novas tecnologias para continuar dando seus conteúdos à distância, escancara-se o desafio da escola pública em lidar com a incógnita da desigualdade social e econômica enfrentadas pela maioria da população brasileira, sendo impossibilitada a universalização de seu acesso à educação não presencial, já que é desprovida de ferramentas tecnológicas.

Pelo necessário isolamento imposto, a alteração de nossas rotinas favoreceu inúmeras percepções acerca da fragilidade da vida humana, dos reflexos dos disparates sociais e econômicos para a dignidade e preservação da vida, da importância de investimentos na área da ciência e da pesquisa para garantia do desenvolvimento econômico e social de uma nação. Contudo, enquanto professora da educação básica da escola pública, indago: Qual seria o papel da educação neste momento? Em tempos de reconfiguração de valores e novos hábitos apreendidos para garantir a sobrevivência, apenas nossa capacitação e adequação às novas ferramentas tecnológicas seriam suficientes para ir ao encontro das novas demandas que a Covid-19 impõe às comunidades que estamos inseridos? Afinal, de que forma o currículo poderia contemplar minimamente uma educação que contribua para a formação humana de modo a atenuar as consequências que a pandemia estabelece?

\section{DA POTÊNCIA DE UM TRABALHO COLETIVO}

A prefeitura de Campinas, por meio da Resolução SME/FUMEC nº 02, de 26 de março de 2020, estabeleceu que, devido ao isolamento social, as ações pedagógicas propostas pela plataforma digital deveriam ter um caráter mitigador e emergencial, diferindo do planejamento das atividades presenciais trimestrais, ressaltando que a interação entre escola e alunos por meio da plataforma não se caracterizariam como educação à distância. Ainda que dispondo de um documento orientador, na escola em que trabalho, em uma das primeiras reuniões virtuais dos professores do Ensino Fundamental II com a gestão pedagógica, os professores não apresentavam coesão sobre o caminho a seguir. Enquanto o silêncio de alguns era manifestado, outros traziam falas em defesa da importância da construção de um trabalho interdisciplinar pautado nos princípios de uma educação humanitária e solidária, sendo contrapostos por proposições de dar continuidade ao trabalho pedagógico por meio de revisões, sendo o livro didático escaneado uma possibilidade de recurso adequado para a nova realidade. Tangível estava que o isolamento social não apenas nos separava fisicamente, mas já nos isolava também acerca da concepção sobre o educar, sendo fincada a distinção no processo pedagógico que se estabeleceria: um grupo de professores decidira descompartimentalizar-se, deixar suas caixinhas de especialistas, iniciando timidamente um diálogo de várias vozes para a construção de um trabalho interdisciplinar que objetiva a promoção de uma escuta solidária de modo a diminuir nos alunos a lacuna emocional imposta pelo distanciamento social, enquanto o outro grupo de professores seguiria seu caminhar de forma independente.

Cecília Meireles (1997, p. 287), afirma que, “por mais que eu sacuda os cabelos, por mais que sacuda o vestido, a poeira do caminho jaz em mim”. Acredito que pelo fato de a nossa formação ter sido pautada por ideais iluministas em que o racionalismo da modernidade pregava o homem como o centro do universo e que por meio da instrução, do saber transmitido na e pela escola, se tornaria um cidadão civilizado e pleno, tenhamos dificuldade enquanto professores de reconhecer que, talvez, um dos maiores desafios para a educação seja se livrar do estigma de que a escola é o local de transmissão de verdades prontas, do conhecimento, somente pelo qual seria possível a transformação do homem em um ser civilizado. É inegável que não seja tarefa fácil nos livrar de tais amarras, pois como aponta Meireles, a poeira jaz em nós, nos constitui. Contudo, precisamos considerar que o isolamento social arrancou nossa normalidade, 
distanciando-nos, privando-nos de afeto e da relação social com o outro, causando um impacto emocional sem precedentes nos adultos, e ainda mais nas crianças e adolescentes que têm a escola como um dos principais meios de interação social. Como a pandemia nos institui em um solo novo, acredito que faz-se necessário o desbravamento de um novo caminho, ainda que com poeira, com resquícios de um solo já batido que sempre nos constituiu, por entender que neste exato momento precisamos fazer da escola espaço/tempo de acolhimento, reconhecendo que os saberes/fazeres dos professores precisam ir além da mera repetição de conteúdos previstos ou a transmissão de conhecimentos alheios, para atentar a real necessidade da construção de novos saberes/fazeres coletivos que o momento sócio-histórico demanda.

Ao iniciar o trabalho interdisciplinar, tínhamos em mente a necessidade da reaproximação dos alunos, quebrando o silêncio que fora abruptamente estabelecido ao cortar nossa rotineira interação com eles. A ideia da gravação de um vídeo de boas-vindas foi levantada como meio de levar até eles uma mensagem tanto de acolhida, reafirmando nossa preocupação e carinho para com eles, assim como nosso relato não apenas como professores, mas como pessoas que também sofriam com as agruras impostas pelo novo inimigo invisível. Estabelecemos que nosso trabalho seria marcado pela acolhida, pela escuta solidária, sendo nossa metodologia o trabalho por meio de projetos, pautados por um eixo norteador que buscaríamos construir dialogicamente com o intuito de desenvolver habilidades e aprimorar o repertório cultural deles, sendo respeitadas as particularidades dos ciclos de aprendizagem, neste caso ciclo III e ciclo IV. Por ainda estar ensaiando os primeiros passos para buscar atender as demandas dos alunos, escrevemos uma carta de apresentação de nossa proposta interdisciplinar de trabalho, assim como elaboramos um questionário para tecer algumas considerações sobre questões emocionais, sociais e econômicas que poderiam estar enfrentando. Pela tabulação dos dados do questionário, foi perceptível o impacto emocional que sofriam, sendo representado pelas palavras "medo", "tristeza”, "entediado(a)”, "preocupado(a)", "falta dos amigos”, "falta dos professores”, “falta das aulas”, externalizando também dificuldades econômicas, bem como sugeriam que trabalhássemos tanto por meio de revisão de conteúdos como por atividades artísticas e culturais.

A partir da interpretação dos gráficos, diálogos foram entrelaçados em meio a um emaranhado de vozes de professores, que carregavam reconfigurações de crenças, de valores, regadas por tristezas e preocupações, assim como nossos alunos também o traziam. Assim, decidimos que seria importante retomar os laços afrouxados pelo isolamento social, propondo uma reunião virtual de acolhida, em que pudessem falar, ouvir ao outro, ouvir a nós professores também, favorecendo, nesta relação dialógica, se enxergar ao ouvir suas dificuldades nas falas professadas pela boca do outro, seu colega, seu professor(a). Tal reencontro expôs ainda mais suas dores ao relatarem seus medos, a saudade dos pais por estarem na casa de avós em outra cidade ou estado, a preocupação com a ausência da mãe por atuar na área da saúde, a dor por já ter pedido um ente querido pela Covid-19, o desabafo honesto do se sentir muitas vezes tristes e solitários.

Mikael Bakhtin (2003) aponta que somos formados na e pela relação dialógica, ressaltando que "quando me olho no espelho, em meus olhos olham olhos alheios; quando me vejo no espelho não vejo o mundo com meus próprios olhos desde o meu interior; vejo a mim mesmo com os olhos do mundoestou possuído pelo outro” (BAKHTIN, 2003, p. 366).

Convergindo com Bakhtin, confesso que o reencontro do meu ser, o eu professor, com meu outro, meu aluno, foi emocionante por emanar em mim a retomada de minha constituição enquanto educadora, que apenas se dá na e pela relação com meu aluno. Nesta relação dialógica, fiquei consternada pela escuta das feridas deles, meus alunos, meu outro, e pude me enxergar ao narrarem suas tristezas, por amalgamarem-se com as minhas próprias dores também, já que também estou sofrendo pela ausência física dos meus pais, podendo vê-los apenas pelo portão, sentindo uma imensa saudade de um abraço, um gesto de afeto tanto deles, como de irmãos, familiares e amigos.

Através do encontro com eles, recebemos informações de que alguns de seus colegas não dispunham de ferramentas tecnológicas e/ou internet disponível para acessar a plataforma, confirmando a hipótese que levantávamos sobre a não universalização de acesso de tantos estudantes nossos. Segundo dados do IBGE divulgados em março de 2020, um a cada quatro brasileiros não tem acesso à internet, representando cerca de 46 milhões de pessoas. Em Campinas, embora o próprio prefeito, Jonas Donizette, tenha veiculado na mídia a compra de um tablete por aluno da rede municipal de ensino, tal aquisição não se 
efetivou, sendo oferecido um chip com internet mais de dois meses após o início da suspensão das aulas, visando a uma maior adesão ao seu acesso digital. A não universalização de acesso se configura como um assunto espinhoso para a educação pública, justamente pela impotência de não conseguir chegar aos alunos mais carentes, sendo estes talvez os que mais precisem por estar sofrendo com as consequências do isolamento social de forma mais intensa, além de serem privados de seu direito à educação e à instrução assegurados pela Constituição Federal (1988), ECA(1990), LDB(1996), os quais preveem seu pleno desenvolvimento e exercício da cidadania em plena igualdade de condições.

Com o objetivo de abranger maior acesso digital dos alunos, a utilização da página do Facebook da escola e os e-mails institucionais criados foram acrescentados como meios de disponibilização das atividades oferecidas. Ora, pelo fato de a Pandemia acentuar e dilatar a desigualdade social e econômica das famílias em geral, em especial as de baixa renda, acredito que seja necessário um olhar cauteloso perante esta nova realidade para que a evasão escolar e o abandono não predominem dada a ruptura com a convivência no espaço escolar.

Tanto o questionário como a reunião virtual serviram de instrumentos de análise da nova configuração do cotidiano da comunidade escolar a qual pertenço, favorecendo a construção de conhecimentos. Concordo com a afirmação de Machado Pais (2003, p. 74) de que o cotidiano deve "ser tomado como o fio condutor do conhecimento", pois torna-se lugar de reflexão, propiciando práticas educativas significativas por entender as demandas dos que ali estão inseridos. Confluindo com Paulo Freire (1996, p. 22), “[...] na formação permanente dos professores, o momento fundamental é o da reflexão crítica sobre a prática. É pensando criticamente a prática de hoje ou de ontem que se pode melhorar a próxima prática [...]” (FREIRE, 1996, p. 22).

Neste processo de pensar minha prática no e pelo cotidiano, especialmente sob a perspectiva atual, entendo que o ensino pautado por conteúdos prescritos torna-se um discurso vazio, sem sentido, dadas as situações de violência física ou simbólica impostas pelo isolamento social. O planejamento pedagógico elaborado individualmente no início do ano deixa de ser coerente com a nova ordem social, precisando ser redesenhado, de modo a reconfigurar meu saber/fazer para dar sentido às novas demandas que se instauram na comunidade escolar. Reflito que as vozes legitimadas nos livros didáticos se enfraquecem de alguma forma neste momento que estamos fora do ambiente escolar, por não responderem aos anseios emergenciais apresentados no hoje. Concluo que o trabalho interdisciplinar se torna essencial por ser suporte diante do novo caminhar por envolver um movimento de vozes, que se atravessam e se entrelaçam, produzindo novos significados e dinamismo no processo de ensinar e aprender.

O trabalho coletivo desenvolvido visa à construção de projetos interdisciplinares a partir de um tema gerador que enfoquem habilidades e não conteúdos propriamente ditos, respeitando os alunos que não têm garantia de acesso. Na semana seguinte que as atividades são propostas, realizamos reuniões virtuais com os alunos propiciando discussões acerca dos temas propostos, sendo já contemplados: assuntos informativos acerca da Covid-19 uma vez que pelo questionário muitos buscavam se informar por fontes não verossímeis; por apresentarem medo do vírus trouxemos a importância de novos hábitos sociais para a preservação da vida; optamos por trabalhar com o tema fake news com o intuito de reconhecerem a importância de checar a fonte da notícia e evitar propagar mensagens que podem desinformar e causar pânico; apontamos as consequências emocionais do isolamento social e as possibilidades de atenuá-los seja pela prática esportiva ou pelo vínculo social remoto; propiciamos a leitura do livro " $\mathrm{O}$ diário de Anne Frank” para propiciar um comparativo entre o momento sócio-histórico vivido por Anne e como ela buscou superá-lo com o presente momento vivido por eles; propusemos o filme "Escritores da liberdade”, realizando dinâmicas de internalização, a fim de apresentar os diferentes tipos de linguagens, escrita, dança, pintura, música, audiovisual, como potências de criação para externalizar as experiências vividas; trabalhamos com o filme "O abraço da serpente" objetivando abordar a dominação na e pela língua como meio de silenciamento cultural e linguístico, apontando a colonização linguística no Brasil e a situação vivida pelos povos indígenas.

É importante ressaltar que embora habilidades tenham sido o foco e não conteúdos novos, e que tanto a construção do trabalho como a interlocução nas reuniões on-line tenham se efetivado por meio de um diálogo interdisciplinar com o intuito de a ampliação de repertório dos alunos, as habilidades abordadas não deixaram de perpassar as especificidades das diferentes áreas de saber envolvidas, não sendo descritas aqui pela brevidade deste documento. 


\section{CONSIDERAÇÕES FINAIS}

Acredito que meu relato se soma a tantos outros trabalhos pautados e desenvolvidos no e pelo cotidiano, com o intuito de ressignificar a prática docente neste momento de pandemia. Sabemos que o papel social da escola é abordado por muitos autores, mas convirjo com as considerações de Paulo Freire (1996) por apontar a não neutralidade no ato de educar, pois as escolhas que fazemos sobre o quê ensinar refletem nossos valores e concepções, e à medida que nos tornamos conscientes disto, percebemos que o quê ensinamos pode causar consequências em nossos alunos, reconhecendo assim a importância de uma prática educativa político-pedagógica para a construção de uma educação crítica e transformadora. Sendo assim, dialogo a partir da concepção freiriana de educação com Michel de Certeau $(1994,1996)$ sobre a questão curricular por acreditar que o cotidiano é o "lugar de resistência”, da "criação anônima”, por ser "aquilo que nos é dado cada dia", favorecendo que os produtos consumidos nos mercados dos bens sejam reapropriados pela "marginalidade de massa" aos seus próprios interesses. Ora, ainda que vivendo sob a direção do currículo formal, prescrito, como educadores, podemos utilizar dos múltiplos saberes tecidos na vida cotidiana dentro e fora da escola para buscar a verdadeira inclusão do aluno, sua formação crítica e inclusiva, conforme aponta Freire (1996). Pensando nas profundas transformações sócio-históricas que a pandemia impõe, gerando instabilidade, medo e reconfiguração de valores, faz-se necessário problematizar a função social da escola para que novas proposições curriculares sejam consideradas, para que não sejam ignoradas as novas demandas que se configuram, sendo promovidas novas práticas pedagógicas que venham ao encontro da formação plena do educando, a qual favoreça sua readequação à nova forma de vida na sociedade atual.

\section{REFERÊNCIAS}

BAKHTIN, M. Estética da criação verbal. Tradução de Paulo Bezerra. São Paulo: Martins Fontes, 2003.

BRASIL. Lei n ${ }^{\circ}$ 9.394. Estabelece as Diretrizes e Bases da Educação Nacional, de 20 de Dezembro de 1996. Diário Oficial da União, Brasília, DF, 23 dez. 1996. P. 27833-41

BRASIL. Constituição da República Federativa do Brasil. Presidência da República. 5 de outubro de 1988. Brasília, DF: Senado Federal: Centro Gráfico: 1988.

BRASIL. Estatuto da Criança e do Adolescente, Câmera dos Deputados, Lei no 8.069, de 13 de julho de 1990. DOU de 16/07/1990 - ECA. Brasília, DF.

CAMPINAS. RESOLUÇÃO SME/FUMEC Nº 002, 26 DE MARÇO DE 2020. Diário Oficial, Campinas, SP, 27 de março de 2020. Disponível em: http://www.campinas.sp.gov.br/uploads/ pdf/930302319.pdf. Acesso em:10 de Junho de 2020.

CERTEAU, M. A invenção do cotidiano: 1. Artes de fazer. Petrópolis: Vozes, 1994.

CERTEAU, M. A invenção do cotidiano: 2. Cozinhar e Morar. Artes de fazer. Petrópolis: Vozes, 1996.

FREIRE, P. Pedagogia da autonomia: saberes necessários à prática educativa. São Paulo: Paz e Terra, 1996.

MEIRELES, C. Poesia Completa, Volume 2. Rio de Janeiro: Nova Fronteira, 1997.

PAIS, J. Vida Cotidiana - enigmas e decifrações. São Paulo: Cortez, 2003.

USO de Internet, televisão e celular no Brasil. Educa IBGE, 2020. Disponível em: https://educa.ibge. gov.br/jovens/materias-especiais/20787-uso-de-internet-televisao-e-celular-no-brasil.html. Acesso em: 10 jun. 2020. 